\title{
Research on the Fracture Resistance of Different Types of Asphalt Mixture Based on the Overlay tester
}

\author{
Wu Xirong \\ Key Laboratory of Highway Construction \& Maintenance Technique in Loess Region, \\ Shanxi Provincial Research Institute of Communications, Taiyuan 030006, Shanxi;
}

Key words: asphalt mixtures; anti-cracking performance; Overlay tester; OT cycles to failure Abstract: In order to study the reflection crack resistance of asphalt mixture, using Overlay tester, crack resistance property of five asphalt mixture types were analyzed based on the repeated loading mode. The paper analysis the influence of mixture types、 temperature and volume index (void ratio)

on the anti-cracking performance. Result show that the dense-graded HMA(AC-13、CAM、SMA -13and Super pave-13) generally exhibited good cracking resistance than open-graded HMA(OGFC-13). For the HMA mixes evaluated based on the Overlay tester. The higher the temperature, the better the crack resistance of asphalt mixture .No distinctive relationship appeared to exist between the peak load and OT cycles. This indicated that OT cycles was not necessarily dependent on the peak load. Similarly, the magnitude of the peak load could not be used as an indicator of the HMA mix cracking resistance.

Cracking (in particular load-associated) is one of the critical distresses prevalent in today's hot-mix asphalt (HMA) pavements. To mitigate this distress, crack-impeding interlayer materials such as geosynthetic interlayers are specified to protect the HMA overlays as part of maintenance and rehabilitation strategies, such as paving grids, paving mats, or paving fabrics and so on. In addition to the above measures, strengthen the anti-cracking performance of asphalt mixture itself plays an important role of delaying the occurrence of cracks on asphalt pavement, therefore, adopt what method and evaluation index which can objectively reflect the anti-cracking performance of asphalt mixture is particularly important.

Low temperature anti-cracking performance evaluation method are many, such as low-temperature bending test, flexural fatigue test, direct tensile fatigue, indirect tensile fatigue, low temperature bending creep test, etc ${ }^{[1-3]}$. The traditional test method of crack resistance of asphalt mixture applied load by the control of constant stress or strain, but it can only measure the occurrence of fatigue cracking and cannot included the crack extension stage. Now finite element method widely used does not contain the occurrence of cracks process ${ }^{[4]}$.Overlay tester (OT) test ${ }^{[5-6]}$ is used to evaluate crack sensitivity in repeated loading mode and load cycles crack failure is used to describe the cracking potential of mixture. Cracking process containing two stage of fracture behavior and fracture happened makes the results more comprehensive.

test equipment

The key components of the OT device, as shown schematically in Fig.1, consists of two steel plates, one fixed and the other able to move horizontally to simulate the opening and closing of joints or cracks in the old pavement beneath an overlay. 


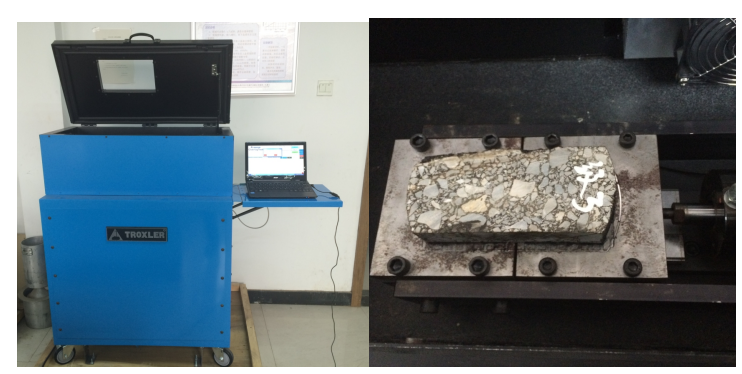

Fig 1 OT setup

\section{Test procedure}

\section{Test temperatures: $25^{\circ} \mathrm{C}$ and $15^{\circ} \mathrm{C}$}

Since HMA mixtures are often temperature sensitive, it is highly recommended that the OT for HMA fracture properties be conducted at two temperatures: 25 and $15^{\circ} \mathrm{C}$.Note that the OT system can be run at a temperature range from $0^{\circ} \mathrm{C}$ to $35^{\circ} \mathrm{C}$.

\section{Maximum Opening Displacements:}

Large MOD often causes the specimen to break too fast rapidly to catch the crack propagation process. Conversely, small MOD makes crack propagation too slow. Both scenarios are not good for determining the HMA fracture properties. Also, temperature has significant influence on HMA crack resistance. After considering all the information, some guidelines for selecting MOD are developed below:

\section{MOD at $25^{\circ} \mathrm{C}$ :}

The regular MOD $(0.63 \mathrm{~mm})$ should be used first. If the cycles to failure (93\% load drop from the maximum load measured at the first cycle) is less than 20 cycles, the MOD must be reduced until the minimum cycles to failure are more than 20 cycles. It has been found that MOD of $0.38 \mathrm{~mm}$ works well in most cases which can't meet the requirement of 20 cycles with MOD $=0.63 \mathrm{~mm}$.

\section{MOD at $15^{\circ} \mathrm{C}$ :}

The proposed MOD at $15^{\circ} \mathrm{C}$ is $0.38 \mathrm{~mm}$. Again, this MOD may be reduced, depending on cycles to failure. If necessary, reduce the MOD until the minimum cycles to failure are more than 20 cycles.

\section{Loading waveform and time:}

A cyclic triangular waveform with10 sec. $(5 \mathrm{sec}$. load plus $5 \mathrm{sec}$. unload) .But both the loading wave form and loading time can be changed, depending on users selection. In current system, both triangular and haversine waveforms are available. Also, the loading time can be changed from 0.04 second per cycle to minutes (or hours) per cycle, depending on user's selection. The reason for the selection of triangular waveform and $10 \mathrm{sec}$. per cycle is to match the current TxDOT standard test procedure: Tex-248-F.

\section{OT specimen:}

One important modification was establishing a standard specimen size of $150 \mathrm{~mm}$ long by $75 \mathrm{~mm}$ wide by $38 \mathrm{~mm}$ high. This size of specimen can be easily cut from samples prepared in the Gyratory Compactor (SGC) or from field cores. The sequence of cutting samples from a laboratory molded specimen is shown in Figure 2.

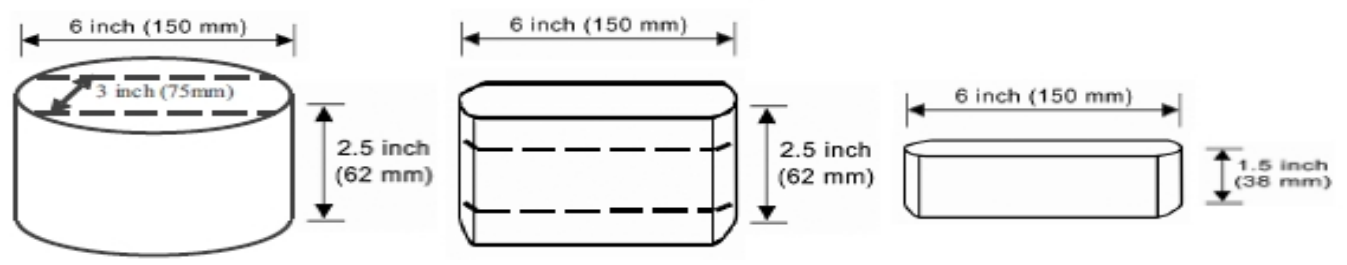

Fig 2 Specimen cutting size 


\section{Experiment materials}

Aggregate is limestone and technical indicators showed in table 1. Asphalt is SBSI-C modified asphalt and its technical indicators showed in table 2.

Tab 1 Technical performances of SBSI-C modified asphalt

\begin{tabular}{cccccc}
\hline penetration & $\begin{array}{l}\text { Penetration } \\
\text { index }\end{array}$ & $\begin{array}{c}\text { ductility } \\
\left(25^{\circ} \mathrm{C}, 100 \mathrm{~g}, 5 \mathrm{~s}\right)\end{array}$ & $\begin{array}{c}\text { dynamic } \\
\text { viscosity }\end{array}$ & $\begin{array}{c}\text { Softening } \\
\text { point }\end{array}$ & $\begin{array}{c}\text { Elastic } \\
\text { recovery } \\
/ 0.1 \mathrm{~mm}\end{array}$ \\
& & $/ \mathrm{cm}$ & $\left(135^{\circ} \mathrm{C}\right) /$ & $/ \%$ \\
& & $($ Pa.s $)$ & & \\
& & & 1.586 & 75.3 & 93 \\
\hline 65.3 & 1.0 & 42.4 & &
\end{tabular}

Tab 2 Technical performances of coarse aggregate

\begin{tabular}{|c|c|c|c|c|c|c|c|}
\hline \multirow{3}{*}{$\begin{array}{c}\text { Crush value } \\
1 \%\end{array}$} & \multirow{3}{*}{$\begin{array}{l}\text { abrasion } \\
\text { loss } / \%\end{array}$} & appare & relative & \multirow{2}{*}{\multicolumn{2}{|c|}{$\begin{array}{l}\text { bulk specific gravity } \\
\qquad\left(\mathrm{g} / \mathrm{cm}^{3}\right)\end{array}$}} & \multirow{2}{*}{\multicolumn{2}{|c|}{$\begin{array}{l}\text { effective density } \\
\qquad\left(\mathrm{g} / \mathrm{cm}^{3}\right)\end{array}$}} \\
\hline & & density & $\left.\mathrm{g} / \mathrm{cm}^{3}\right)$ & & & & \\
\hline & & $5-10 \mathrm{~mm}$ & $10-15 \mathrm{~mm}$ & $5-10 \mathrm{~mm}$ & $10-15 \mathrm{~mm}$ & $5-10 \mathrm{~mm}$ & $10-15 \mathrm{~mm}$ \\
\hline 12.5 & 15.6 & 2.776 & 2.785 & 2.738 & 2.723 & 2.750 & 2.762 \\
\hline
\end{tabular}

\section{Determination of graduation}

Experiments adopted five different types of gradation, respectively of fine gradation CAM ${ }^{[7-8]}$, gap gradation SMA-13, open gradation OGFC-13, continuous gradation AC-13 and Superpave-13.Composition gradation are shown in table 3.

Tab 3 Design gradation

\begin{tabular}{ccccccccccc}
\hline & \multicolumn{8}{c}{ aggregate quality percentage $(\%)$} \\
gradation types & 16.0 & 13.2 & 9.5 & 4.75 & 2.36 & 1.18 & 0.60 & 0.30 & 0.15 & 0.075 \\
\hline AC-13 & 100 & 91.1 & 75.2 & 46.8 & 36.7 & 23.1 & 17.7 & 10.5 & 7.0 & 6.0 \\
SMA-13 & 100 & 90.0 & 70.5 & 33.1 & 23.9 & 19.2 & 17.3 & 14.9 & 13.5 & 12.5 \\
CAM-13 & 100.0 & 95.0 & 87.0 & 74.0 & 57.0 & 0 & 26.0 & 14.0 & 6.0 & 5.0 \\
OGFC-13 & 100 & 95 & 64 & 27.5 & 20 & 14.5 & 10.8 & 8 & 5.5 & 4 \\
Superpave-13 & 100 & 94.4 & 84.1 & 59.4 & 31.1 & 25.3 & 19.1 & 14.6 & 12.9 & 9.5 \\
\hline
\end{tabular}

\section{The optimal asphalt content}

Based on the Marshall method, AC-13, SMA-13, CAM-13 and OGFC-13 were designed and the optimum asphalt content respectively. are $4.9 \%, 5.4 \%, 5.8 \%$ and $4.9 \%$, additionally ,the rotating compaction forming method is adopted to Superpave13 mixture design and the optimum asphalt content of Superpave13 is $5.0 \%$. 


\section{Anti-cracking performance evaluation parameters}

\section{Fracture parameters}

At present, based on the stress intensity factor of empirical Paris formula ${ }^{[9-10]}$, the fatigue crack propagation process of asphalt pavement is widely described and calculated .Paris' law-the most often used crack propagation laws- is presented in Equation (1).

$$
\frac{d c}{d N}=A(K)^{n} \backslash
$$

Where $\mathrm{c}$ is crack length, $\mathrm{N}$ is the number of load repetitions, $d c / d N$ is crack speed or rate of crack growth, $\Delta k$ is change of stress intensity factor during loading and unloading, and $\mathrm{A}$ and $\mathrm{N}$ are fracture properties of material. Due to the heterogeneity, uneven porosity distribution and residual stress of specimen, the expansion of crack is a very complicated process. Therefore, crack length is calculated by the finite element software on the basis of some assumptions. So, it is limited to distinguish and judge the crack resistance of asphalt mixture using the fracture parameters $\mathrm{A}$ and $\mathrm{N}$.

\section{OT test evaluation parameters}

At present, OT test has two loading modes, one is a monotonic loading mode, considering the FE Index as a HMA fracture parameter. The other is repeated loading mode, considering the OT

cycles as a HMA fracture parameter ${ }^{[11-12]}$ 。 This article uses the way of repeating loading. The standards of Texas asphalt mixture test sample is qualified or not is that load cycles is more than 300 times $^{[13]}$. The 300 pass-fail screening criterion has generally yielded satisfactory field performance results with most Texas dense-graded and gap-graded (SMA) mixes. However, this tentative criterion might not be universally applicable to all HMA mix types or site specific project requirements ${ }^{[14]}$ 。

\section{Crack resistance test results and analysis}

Samples of five kinds of asphalt mixtures were tested by way of repeated loading. The temperature of test is $25^{\circ} \mathrm{C}$ and the load loading rate of $3.125 \mathrm{~mm} / \mathrm{min}$. When peak load decayed to $93 \%$, the test equipment automatically stop. Test method and procedure for reference OT test standard and test results summary as follows in table 4.

Tab 4 OT test results of five kinds of asphalt mixture

\begin{tabular}{cccccc}
\hline Grading types & mixture types & $\begin{array}{c}\text { Optimum } \\
\text { asphalt } \\
\text { content }\end{array}$ & void content & Peak load & cycles \\
\hline fine gradation & CAM & $5.8 \%$ & $3.5 \%$ & 2.6 & 514 \\
dense gradation & AC-13 & $4.9 \%$ & $3.4 \%$ & 3.7 & 247 \\
gap gradation & SMA-13 & $5.4 \%$ & $3.4 \%$ & 3.75 & 300 \\
open gradation & OGFC-13 & $4.9 \%$ & $20 \%$ & 2.1 & 103 \\
dense gradation & Superpave-13 & $5.0 \%$ & $4 \%$ & 1.13 & 660 \\
\hline
\end{tabular}

Can be seen from the test result of fine gradation, dense gradation, gap gradation and open gradation mixture, the number of load cycles of Superpave13 is most, followed by SMA-13 and 
CAM-13, the least mixture load cycles is OGFC-13.Therefore, the crack resistance of the dense gradation asphalt mixture (small pore) compared to of open graded (large pore) asphalt mixture has obvious advantages.

For the HMA mixes evaluated, no distinctive relationship appeared to exist between the initial load and OT cycles as shown in Fig.5. This indicated that the OT cycles. was not necessarily dependent on the initial peak load. Similarly, the magnitude of the initial load could not be used as an indicator of the HMA mix cracking resistance. General theoretical expectations would.

\section{The temperature sensitivity analysis}

SMA-13 and AC-13 as research objects, under the condition of optimum asphalt content and three groups of sample were formed. Temperature, respectively, was set to $10{ }^{\circ} \mathrm{C}, 20{ }^{\circ} \mathrm{C}$ and $30{ }^{\circ} \mathrm{C}$ and the test result is shown in figure3.

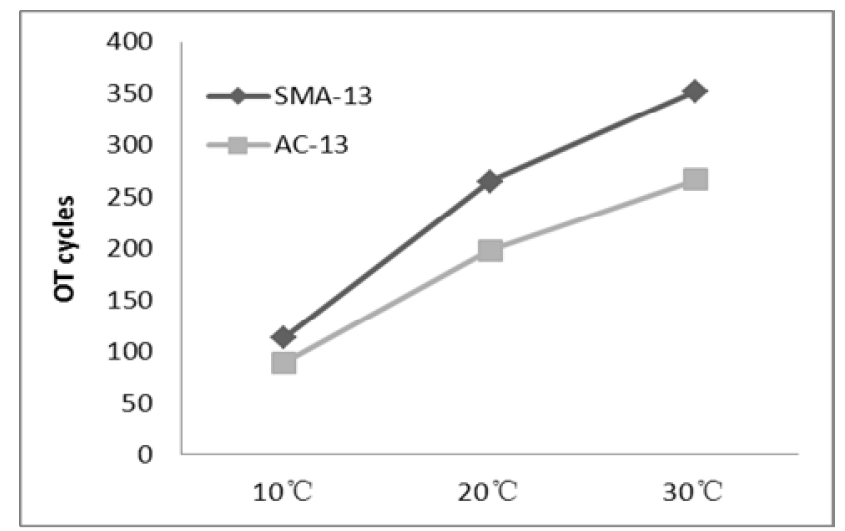

Fig 3 Effect of temperature on the anti-cracking performance

From fig3, we can see that the influence of temperature on OT cycles is consistent: the increasing in temperature increases the flexibility of the asphalt mixture, so as to improve the anti-cracking performance of asphalt mixture.

\section{Conclusions}

(1) This indicated that the OT cycle was not necessarily dependent on the initial peak load. Similarly, the magnitude of the initial load could not be used as an indicator of the HMA mix cracking resistance.

(2) The influence of temperature on the cycle number is consistent: The increasing in temperature increases the flexibility of the asphalt mixture, so as to improve the anti-cracking performance of asphalt mixture.

(3) The characteristics of the structure and the composition of the mixture material are affecting the fracture properties of asphalt mixture, the fine- and dense-graded HMA mixes compared with open-and coarse-graded HMA mixes generally exhibited good cracking resistance in the laboratory. Therefore, in the process of asphalt mixture design, it is better not using the open-and coarse-graded HMA mixes when considering the good crack resistance of mixture.

(4) In general, the HMA mix cracking resistance was observed to be a function of the mix-design characteristics and volumetric properties including the material type (e.g., PG 76-22S and granite aggregates performed well), asphalt-binder content, AV content and so on.

(5) The ultimate field performance of any given HMA mixes is also a function of many other interactive variables such as the pavement structure (i.e., layer thicknesses, number of layers, 
location of the HMA layer, etc.), traffic, environmental conditions, construction effects (i.e., construction methods and quality control), etc. All these factors need to be considered when evaluating or predicting the overall expected cracking performance of a mix in the field.

\section{References}

[1] Liu Tao, Hao Peiwen. Comparison Study of Evaluation Method for Low Temperature Anti-cracking Performance of Hot Mix Asphalt $[\mathrm{J}]$. Journal of Tongji University (Science and Technology), 2002, 30 (12): 1468-1471.

[2] Zhang Hong. Evaluation Methods of Asphalt-mixture's Anti-cracking Performance at Low Temperature $[\mathrm{J}]$. Journal of Xi'an Highway University (Science and Technology), 2002, $22(4): 5-8$.

[3] Liu Dong, Yang Zhaohui. Anti-cracking Performance Evaluation of AC-16 Asphalt Mixture [J] .Highway Engineering, 2011, 36 (6) 134-148.

[4] Li Xinhai, Zhou Xuli, Zhang Tao. Based on Overlay Tester Tests to Evaluate the Ability of Reflective Crack of Asphalt Mixture [J] . Journal of China \& Foreign Highway, 2015, 35 (3) : 303-305.

[5] Zhou F, T Scullion. Overlay Tester: A Simple Performance Test for Thermal Reflective Cracking $[\mathrm{J}]$.Journal of the Association of Asphalt Paving Technologists. Long Beach CA USA, 2005(74):443-484.

[6] Zhou, F., S. Hu, T. Scullion, M. Mikhail, and L. F. Walubita. A Balanced HMA Mix Design Procedure for Overlays $[\mathrm{J}]$.Journal of the Association of Asphalt Paving Technologists, 2005(74):443-484.

[7] TxDOT. Special Specification 3109(ss3109): Crack Attenuating Mixture CAM [Z] . Internal Publication, Austin, Texas; 2004.

[8] Wu Zhiyong. A Design and Research on Ease Cracked Asphalt Mixture [D] .changsha: Changsha University,2008.10-16.

[9] Paris P, Gomez M, Anderson W. A Rational Analytic Theory of Fatigue [J].Trend on Eingineering,1961(13):9-14.

[10] Liu Wen,Xu Shilang,Li Qinghua. Theorical and Experimental Study on Fatigue Crack Prapagation Law of Ultra-High tou Ghness Cementitions Composite [ J ] .Engineering Mechanics,2013,30(11):67-74.

[11] Lubinda F.Walubita, Abu N.M.Faruk, Allex E.Alvares, Tom Scullion.The Overlay Tester (OT):Using the Fracture Energy Index Concept to Analyze the OT Monotonic Loading Test Data [J] .Construction and Building Materials. 2013(40):801-811.

[12] Jinsu li, Jeongho Oh, Bhaven Naik, Geoffrey S. Simate, Lubinda F.Walubita. Laboratory Characterization of Cracking-Resistance Potential of Asphalt Mixes Using Overlay Tester[J]. Construction and Building Materials. 2014(70):130-140.

[13] Yan Xiangpeng, Yan Xiaoyu. Analysis on the Crack Resistance Test Method of Asphalt Mixture Based on the Overlay Tester $[\mathrm{J}]$. Shandong transportation technology, 2014(5):65-67.

[14] Walubita LF, Hoeffner JK, Scullion T. New generation mix-designs: Laboratory Field Testing and Modifications to Texas HMA Mix-design Procedures. Technical research report 
FHWA/TX-12/0-6132-3. USA: FHWA, Texas A\&M Transportation Institute (TTI); 2013. 